\title{
O ENSINO DOS CONECTORES COM USO DE FORMULÁRIOS DO GOOGLE TEACHING CONNECTIVES USING GOOGLE FORMS
}

\section{Bougleux Bonjardim da Silva Carmo ${ }^{1}$}

Resumo: Neste artigo discute-se o tratamento didático dos conectores com uso do Google Forms. Nesse contexto, reflete-se na relação entre o ensino da coesão sequencial (KOCH, 2010), os estudos dos marcadores discursivos (ALOMBA RIBEIRO, 2005; PORTOLÉS, 2001) e a pedagogia dos multiletramentos (LEMKE, 2010; ROJO, 2012). Metodologicamente, realiza-se a abordagem teórica dos conceitos para transposição didática e, em seguida, expõe-se a utilização dos formulários. Com isso, amplia-se as propostas de construção dos materiais-fonte, conforme Mendes (2012), mediante emprego de ferramentas em diferentes suportes midiáticos para diversificação metodológica e ensino da articulação textual na Educação Básica.

Palavras-chave: Conectores; Google forms; multiletramentos; didática; coesão.

Abstract: This paper discusses the didactic treatment of the connectives using Google Forms. In this context, it reflects in the relationship between the cohesion teaching $(\mathrm{KOCH}, 2010)$, the studies of discourse markers (ALOMBA RIBEIRO, 2005; PORTOLÉS, 2001) and the multiliteracies pedagogy (LEMKE, 2010; ROJO, 2012). Methodologically, it shows the theoretical approach of the concepts for didactic transposition and, then, how to use the forms according this work. So, the proposals of source-materials construction, in accordance with Mendes (2012), are extended through the employ of tools in diferente media supports for methodological diversification and textual articulation teaching in the Basic Education.

Keywords: Connectives; Google Forms; multiliteracies; didactic; cohesion.

\section{Introdução}

O presente trabalho se insere nas discussões acerca da relação entre o ensino de língua portuguesa e o uso das Tecnologias da Informação e Comunicação - TIC ou das Tecnologias Digitais da Informação e Comunicação (FONTANA; CORDENONSI, 2015), bem como

\footnotetext{
1 Mestre em Letras pelo Profletras na Universidade Federal de Santa Cruz e doutorando em Estado e Sociedade pela Universidade Federal do Sul da Bahia. Professor de língua portuguesa da Secretaria de Educação do Estado da Bahia. Tem experiência na área de Letras, com ênfase em Língua Portuguesa, atuando principalmente nos seguintes temas: marcadores discursivos, pragmática, multimodalidade, tirinhas, literatura adaptada e, devido a formação na área da Linguística Forense, dedica-se à Análise da Conversa Etnometodológica. Além dos temas na área de Letras e Linguística, o projeto de tese, no âmbito do Programa de Pós-Graduação em Estado e Sociedade (PPGES / UFSB), dialoga estudos da Memória Social e do Discurso para compreensão das representações sociais e de determinados processos de subjetivação. E-mail: bougleuxcpmatnre7@gmail.com
} 
constitui-se numa ampliação das experiências voltadas para o trato dos marcadores discursivos (doravante MD) e suas diversas subcategorias, dentre elas, os conectores argumentativos. Com efeito, Carmo (2015) e Carmo e Alomba Ribeiro (2014; 2016) delineiam determinadas estratégias de transposição didática relativas à coesão sequencial e articulação textual, com fins apoiar o processo de ensino-aprendizagem desses elementos que exigem domínio do uso dos MD e como forma de complementar a abordagem dos materiais didáticos. Para tanto, este artigo expõe aprofundamentos concernentes às possibilidades de criação ou adaptação de materiais-fonte, com base nas sugestões de Mendes (2012) para o ensino de línguas, como complementos dos livros didáticos de português (CARMO; ALOMBA RIBEIRO, 2014; CARMO, 2015).

Nessa perspectiva, a abordagem linguística deve valer-se de diferentes tipos e configurações de materiais didáticos para o desenvolvimento das diversas competências e habilidades requeridas, além dos recursos que favoreçam à interação com os elementos linguístico-culturais (MENDES, 2012). No presente estudo, a produção de materiais e estratégias didáticas voltam-se para o desenvolvimento da competência discursiva discente, consoante Oliveira (2010), notadamente, fundamentada no uso dos MD na produção escrita, na leitura e interpretação textual (KOCH, 2010; KOCH; ELIAS, 2016).

Diante desses pressupostos, o presente artigo focaliza a discussão do ensino dos conectores argumentativos mediante uso de formulários Google como estratégia de multiletramento. Embora a natureza metodológica desta pesquisa seja, precipuamente, de cunho teórico, trata-se de uma exposição de resultados de pesquisas, práticas e de proposições voltadas para o Ensino Fundamental, séries finais, e Ensino Médio. Nessas condições, há a subsunção de aplicações e experiências considerando as diversas exigências do contexto de ensino, tais como a presença das TIC ou das TDIC como uma realidade inconteste no espaço escolar (FONTANA, CONDENONSI, 2015; SILVA, 2013). Daí a assunção da pedagogia dos multiletramentos para dar conta dos diferentes suportes, formas de leitura, produção textual e cognição (ROJO, 2012).

Paralelamente, os conceitos sobre MD e suas subcategorias de conectores são oriundos dos pressupostos que os concebem como uma classe pragmática essencial no processo textual-comunicativo (ALOMBA RIBEIRO, 2005; ANSCOMBRE; DUCROT, 1994; KOCH, 1987; 2010; PORTOLÉS, 2001). Igualmente, tendo em conta a perspectiva do ensino voltada para o uso das tecnologias, busca-se na Teoria dos Multiletramentos (LEMKE, 2010; NEW 
LONDON GROUP, 1996; ROJO, 2012) os fundamentos para uma didática da língua portuguesa alicerçadas nas necessidades contemporâneas e, por fim, da configuração dos chamados materiais-fonte em diferentes suportes (CARMO, 2015; MENDES, 2012).

Portanto, importa refletir na diversificação metodológica e no usufruto dos diferentes recursos tecnológicos não só como fator de interesse por parte dos (as) discentes, como será mostrado pelo marco teórico, como também pelos novos modos de cognição, leitura e apropriação do conhecimento nas e pelas TIC ou TDIC (ROJO, 2012). Ainda assim, coaduna-se com Rojo e Moura (2012, p. 08) quanto à importância de se fomentar protótipos didáticos para os multiletramentos, ou seja, a criação de "estruturas flexíveis e vazadas que permitem modificações por parte daqueles que queiram utilizá-las em outros contextos que não o das propostas iniciais". Nesse sentido, a proposta aqui levantada é também um protótipo didático por revestir-se dessa natureza flexível ao sabor da criatividade docente (OLIVEIRA; ALENCAR, 2012).

Para clareza expositiva, o artigo assim se apresenta: na primeira seção são expostos os conceitos fundamentais para transposição didática concernentes à natureza dos MD e da subcategoria dos conectores argumentativos. Na sequência, são elencados os aspectos centrais dos multiletramentos que fundamentam a presente discussão. Finalmente, delineia-se a proposta de uso dos Google Forms para o ensino dos MD conectores.

\section{Marcadores Discursivos, Conectores e Coesão sequencial}

\subsection{Da Natureza dos Marcadores Discursivos}

Os marcadores discursivos (MD) se tornaram um dos objetos de estudo centrais na Ciência Linguística desde a virada pragmática, tendo em conta a percepção de diversas unidades lexicais com difícil enquadramento taxionômico, nos termos da classificação morfossintática tradicional (ALOMBA RIBEIRO, 2005), ainda que tal dificuldade de categorização de determinados itens já fosse percebida por diversos gramáticos latinos como partes da oração (FORTES, 2008). Nessas condições, diferentes unidades conjuncionais, adverbiais e interjeicionais mostram uma expansão semântico-pragmática que saltam às funções prototípicas postuladas na descrição gramatical e, por essas razões, é que tornou-se possível a configuração de diferentes abordagens para o fenômeno dos $\mathrm{MD}$, tendo em conta a emergência da visão 
semântico-argumentativa e pragmática da comunicação, do uso da linguagem na enunciação e na produção discursiva (ANSCOMBRE; DUCROT, 1994; PORTOLÉS, 2001).

Em virtude da existência de diferentes abordagens acerca dos MD, para efeitos de vinculação teórica, a concepção dos MD depende, em primeiro lugar, de assumir a visão argumentativa da enunciação que, por sua vez, concebe a estrutura linguística como portadora de instruções semânticas que sinalizam as operações discursivas autorreferenciais (PORTOLÉS, 2001). Por tal razão, enunciação e a estrutura do enunciado apresentam, em si mesmas, as constrições que estabelecem a argumentação, concebida como concatenação de segmentos discursivos. Mais ainda, essa estruturação do enunciado pressupõe a interveniência polifônica do discurso e de uma pragmática integrada à própria condição da linguagem (ANSCOMBRE; DUCROT, 1994; KOCH, 1987; KOCH; ELIAS, 2016).

Em segundo, postular a comunicação como um processo cooperativo, nos termos de Grice (1975), bem como compreender a linguagem como forma de ação no mundo, uma vez que proferir algo, isto é, enunciar ou dizer, é mais do que descrever ou representar, mas executar uma ação (AUSTIN, 1990). A partir disso, perceber que essa ação se estabelece como uma condição natural, cognitiva e pela qual continuamente estamos a interpretar as intenções do outro no processo de interação. Em outros termos, nossa ação no mundo, via linguagem, é ostensiva e intersubjetivamente constituída (PORTOLÉS, 2001; SPERBER; WILSON, 2001).

Numa terceira dimensão, assumir que, em geral, dos signos linguísticos que utilizamos, parte deles opera discursivamente com sentidos representacionais e conceituais, enquanto outros operam predominantemente com funções de processamento cognitivo (BLAKEMORE, 2000; MORAIS, 2011; PORTOLÉS, 2001). Desse modo, de um lado, pode-se perceber que expressões nominais, verbais e adjetivais, por exemplo, corroboram na construção intersubjetiva dos objetos de discurso, tal como postulam Mondada e Dubois (2016), mediante estratégias de nominalização e (re)categorização dos seres, pessoas, objetos, coisas etc. evocados no discurso. De outro, determinados signos funcionam como elementos de sinalização das intenções discursivas e do processamento cognitivo do percurso inferencial. Quer dizer, atuam como sinalizadores da direção dos elementos discursivos que estão subentendidos ou pressupostos no enunciado, expressam à vinculação a cena da enunciação, organizam a tessitura e o encadeamento do discurso (ALOMBA RIBEIRO, 2005; KOCH, 2010; MORAIS, 2011; PORTOLÉS, 2001). 
Portanto, é no balizamento dessas acepções que os MD se caracterizam como unidades voltadas para o processamento relativo ao esforço cognitivo no decurso da intepretação dos enunciados (MORAIS, 2011; ANTÔNIO, 2016). De fato, Koch (1987) postula que os chamados operadores argumentativos contribuem para facilitar a leitura e a interpretação textual por evidenciarem as relações e vínculos semânticos transfrásticos. Isso quer dizer que, embora o encadeamento retórico-discursivo da enunciação indique as relações argumentativas e as vinculações semânticas entre os segmentos, os MD ajudam a diminuir o esforço cognitivo da interpretação pragmática, consoante os autores supracitados. Considerando as diferentes abordagens sobre os MD e seus pontos consonantes, são propriedades dessas unidades: (i) a facilitação do processamento discursivo; (ii) a explicitação dos sentidos e significados implícitos e: (iii) apresentar estatuto subsidiário, dependente dos elementos aos quais se vinculam no discurso e no contexto (PENHAVEL, 2012).

Tendo por base as dimensões discutidas, define-se os MD como unidades que atuam como guias das inferências produzidas na comunicação, mediante as instruções formulativas, informativas e argumentativas que portam e, situando-se subsidiariamente à predicação oracional, facilitam o processamento discursivo (ALOMBA RIBEIRO, 2005; MORAIS, 2011; PORTOLÉS, 2001). Os MD possuem suas subcategorias, dentre elas os conectores argumentativos, formadas por unidades invariáveis, quais sejam, conjunções, advérbios e interjeições (PORTOLÉS, 2001).

\subsection{Os Conectores Argumentativos do Português Brasileiro}

Urge destacar que existem diferentes terminologias para os vários itens que se inserem no campo de estudo dos MD e tal fator deve-se às diversas orientações teóricas (PENHAVEL, 2012). Neste trabalho, adota-se a taxionomia proposta por Portolés (2001), que vale-se da síntese de diferentes correntes teóricas, bem como por meio das instruções semânticas que permitem dar conta dos diferentes significados que um mesmo MD pode assumir, conforme o contexto. Assim posto, segue a classificação adotada:

Imagem 1: Classificação dos Marcadores do Discurso

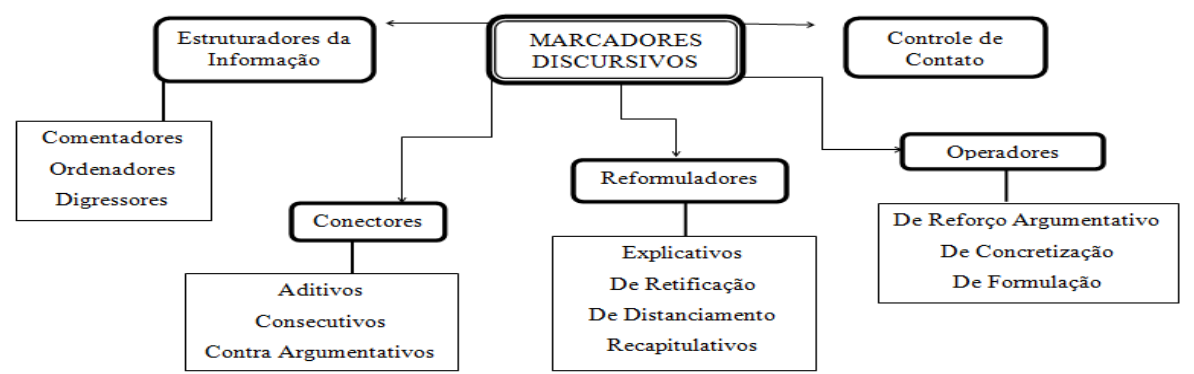


Fonte: Portolés (2001) - adaptado pelo autor.

Para os fins deste trabalho, a didatização dos MD, consoante os objetivos determinados, se concentra no grupo dos conectores que, segundo Portolés (2001), tem a função de vincular semântica e pragmaticamente um membro do discurso ao outro, ao passo que as suposições contextuais são facilmente acessíveis. Com isso, "el significado del conector proporciona una serie de instrucciones argumentativas que guían las inferencias que se han de obtener del conjunto de los miembros relacionados" (PORTOLÉS, 2001, p. 139). Nesse âmbito, não apresentamos uma problematização conceitual, senão expomos uma caracterização dos subgrupos com fins à abordagem proposta.

Sendo assim, urge endossar que a noção de MD atrela-se mais à função assumida pragmaticamente num determinado contexto comunicativo, do que seu pertencimento a determinada classe gramatical. Segundo Martelotta (2011), as funções exercidas pelos conectores advém de um longo e gradual processo de gramaticalização, porquanto as unidades passaram a exercer funções mais gramaticais e, no português brasileiro, tem-se algumas unidades prototípicas ou especializadas no conjunto, a saber:

Quadro 1: Conjunto dos conectores argumentativos

\begin{tabular}{|l|l|l|}
\hline Marcadores Discursivos & \multicolumn{2}{|c|}{$\begin{array}{l}\text { Além disso, igualmente, como também, mas também, ainda, nem, e, } \\
\text { não só, além do mais, ainda por cima etc. }\end{array}$} \\
\cline { 2 - 3 } Conectores & Aditivos & $\begin{array}{l}\text { Já que, visto que, uma vez que, de tal maneira que, de forma que, de } \\
\text { sorte que, portanto, por isso, logo, em consequência, por } \\
\text { conseguinte, em decorrência, por essa razão etc. }\end{array}$ \\
\cline { 2 - 3 } & Contra-argumentativos & $\begin{array}{l}\text { Mas, porém, entretanto, contudo, no entanto, todavia, em } \\
\text { contrapartida, por outro lado, ao contrário, não obstante, se bem que, } \\
\text { embora, ainda que, apesar de, senão, mesmo que, posto que etc. }\end{array}$ \\
\hline
\end{tabular}

Fonte: Koch e Elias (2016); Portolés (2001) - adaptado pelo autor

Como se vê, conjunções e locuções coordenativas e subordinativas, bem como determinados advérbios e locuções adverbiais compõem o grupo. As unidades podem enlaçar 
segmentos que exibem relações lógico-semânticas no nível sentencial (ANTUNES, 2005; KOCH, 1987) e segmentos discursivos argumentativamente relacionados inter-sentencialmente e segmentos maiores relacionados aos episódios discursivos (DIJK, 2008; PORTOLÉS, 2001). Vale destacar que muitos desse conectores têm maior recorrência em determinada modalidade, isto é, transitam entre a oralidade e a escrita (URBANO, 1999). Em todo caso, isso se deve à natureza dos MD que ora se comportam orientados à interação comunicativa, ora orientados à articulação textual-discursiva, com destacado papel na articulação tópica do discurso (KOCH, 1987; 2010; PENHAVEL, 2012).

Diante desses postulados, os conectores aditivos podem ser definidos como introdutores, precipuamente, de argumentos na mesma direção ou orientação argumentativa e que possuem o mesmo "peso" no encadeamento, em razão dos acréscimos de informações (ANTUNES, 2005; KOCH, 1987; PORTOLÉS, 2001). Essa vinculação resulta do fato de que as conclusões das inferências seriam difíceis sem a concatenação dos argumentos relacionados.

Quanto aos consecutivos, postula-se que esses conectores apresentam um membro do discurso que caracteriza-se como uma consequência do anterior, como resultado de um raciocínio ou de um estado de coisas que se exprime em função de outro estado de coisas, tais como relações de conclusão, continuidade tópica etc. (ANTUNES, 2005; KOCH, 1987, 2010; PORTOLÉS, 2001).

No que tange aos contra-argumentativos, se caracterizam pela antiorientação por introduzirem um argumento que contraria as conclusões determinadas pelo anterior, isto é, apresentam um argumento favorável à uma conclusão oposta (ALOMBA RIBEIRO, 2005; KOCH; ELIAS, 2016; NEVES, 2000). Os itens desse grupo, no qual se inserem advérbios e conjunções coordenativas adversativas e subordinativas concessivas, atuam como supressores, atenuadores, ora anulando ou restringindo alguma conclusão que se podia obter com o primeiro argumento (PORTOLÉS, 2001).

Os conectores são essenciais na articulação textual, notoriamente, nos gêneros da ordem do argumentar e no estabelecimento da coerência textual mediante a coesão sequencial (KOCH; ELIAS, 2016). Com isso, a proposta deste trabalho mescla diferentes gêneros textuais, modalidades e temáticas para dar conta do comportamento e uso dos MD conectores, bem como 
da possível ampliação e adaptação, conforme apontado introdutoriamente. Na sequência, importa destacar aspectos centrais quanto à coesão sequencial e sua inter-relação com o uso dos MD.

\subsection{Coesão sequencial, argumentação e coerência}

Os MD são um recurso linguístico-argumentativo utilizado conforme às intenções comunicativas e, por essa razão, no ensino de línguas é preciso ter atenção quanto às possibilidades de uso, embora não se reduzam aos aspectos da coesão sequencial (PORTOLÉS, 2001), mas em outros processos de interação comunicacional, tais como a articulação textual, o encadeamento do discurso e a orientação argumentativa (KOCH, 2010).

Assim, é preciso, como afirma Koch (1987; 2010), levar os (as) discentes ao conhecimento das relações de lógico-discursivas, de como se estabelece a coerência textual a partir do uso adequado dos conectores, como fator de concatenação das ideias presentes no discurso-texto e, por fim, para o balizamento das intenções comunicativas presentes naquilo que está inferido, pressuposto e subentendido. Além disso, "diz respeito aos procedimentos linguísticos por meio dos quais se estabelecem, entre segmentos do texto (enunciados, partes de enunciados, parágrafos e sequências textuais), diversos tipos de relações semânticas e/ou pragmáticas, à medida que se faz o texto progredir" (KOCH, 2010, p. 33).

$\mathrm{Na}$ interdependência entre coesão sequencial, argumentação e coerência, Koch e Elias (2016) postulam a necessidade do domínio desse processo para o estabelecimento da força argumentativa e do direcionamento dos sentidos, já que os MD, chamados pelas autoras de operadores argumentativos, corroboram para indicar quais argumentos são mais fracos ou fortes, introduzir diferentes escalas argumentativas, num processo que se efetiva, em certa medida, intuitivamente pelos interlocutores, tanto em textos escritos quanto orais (PORTOLÉS, 2001).

No caso dos gêneros textuais escritos nos quais, geralmente, a pobreza contextual é maior, faz-se necessário a ampliação daquilo que é dito ou expresso e, por tal motivo, os MD são meios "para facilitar a articulação entre o dito e o contexto" (PORTOLÉS, 2001, tradução nossa). Em virtude de suas funções metadiscursivas, é provável a interveniência de MD em determinados pontos da articulação, como afirma o referido autor. Todavia, consoante Koch (2010) e Koch e Elias (2016), esses itens são parte do repertório da língua e é preciso levar ao domínio do uso para ampliação da criatividade em diferentes contextos comunicativos. 
Convém destacar que a abordagem dos MD e dos conectores argumentativos carecem de maiores aprofundamentos em diversos sentidos nos livros didáticos de língua portuguesa. Para Carmo (2015) ainda é incipiente o quantitativo de atividades e formas de tratamento destinadas ao desenvolvimento da competência discursiva concernente ao uso dessas unidades. Guimarães (2003) endossa que a abordagem da conexão textual também se apresenta desarticulada ou fragmentada em relação às atividades de leitura, trabalho com a gramática e produção de textos, "pois não propõe a análise dos recursos linguísticos utilizados pelo autor no processo de construção do texto" (GUIMARÃES, 2003 p. 153).

A referida autora aponta para a falta de reflexão no uso dos procedimentos de conexão textual, já que as propostas nos livros didáticos "se prendem muito mais à análise gramatical das conjunções do que à reflexão sobre o uso das mesmas no texto" (GUIMARÃES, 2003, p. 154). Assim, sugere-se tratar da reflexão das relações e vinculações dos objetos discursivos no processo de coesão, tratar comparativamente o uso dos conectores, sem desvincular sua análise em relação ao texto onde ocorre e, por fim, trabalhar não só os aspectos de ligação, mas também os aspectos de segmentação e dos tipos de discurso vinculados pelos conectores (GUIMARÃES, 2003).

Considerando que a produção, circulação e consumo de textos se efetivam num conjunto de práticas com novas configurações linguísticas, semióticas e variados suportes, bem como o uso dos MD se estabelece em quaisquer situações comunicativas, torna-se fundamental valer-se de uma pedagogia que dê conta de tratar didaticamente essa rede de relações. Trata-se, então, da perspectiva dos multiletramentos, conforme será exposto a seguir.

\section{Multiletramentos no Ensino de Língua Portuguesa: alguns apontamentos}

O conceito de multiletramento, desenvolvido inicialmente pelo New London Group (1996), constitui-se num alargamento epistemológico relativo ao conceito de letramento. A partir da discussão entre expressivos linguistas e pesquisadores, das mais variadas origens e de diferentes linhas de pesquisa, chegou-se à concepção da pedagogia dos multiletramentos com base nos seguintes argumentos: (i) a condição de diferentes formas de significar e produzir significado no mundo contemporâneo; (ii) a multiplicidade e integração desses significados e modos de produção de sentidos concernentes ao universo midiático, digital, tecnológico e comunicacional; (iii) a natureza contemporânea da conectividade global que perpassa as práticas 
sociais no âmbito privado, no mundo do trabalho, no contexto cultural, nas relações entre o público e o privado e assim por diante (NEW LONDON GROUP, 1996; ROJO, 2012).

Além desses pressupostos, há a assunção de duas perspectivas centrais. A primeira impõe considerar a multiculturalidade inerente à condição da modernidade tardia, que se desenvolve no hibridismo cultural, linguístico, comunicacional e social. Isto é, as populações estão em permanente contato em diversos níveis numa mesclagem profunda de práticas, fazeres e essências desfazendo o binarismo basilar da modernidade e, nesse sentido, o central/periférico, erudito/popular e tantas outras posições dicotômicas, caras ao pensamento moderno ocidental, são dissolvidos num intricado processo de escolhas e coleções (ROJO, 2012). Sob essa ótica, é fundamental pensar as práticas multiletradas no espaço escolar e no âmbito do ensino de língua portuguesa compreendendo a profundidade dessas novas relações que, em diferentes medidas, ecoam na caracterização tanto dos sujeitos, quanto das práticas e interações.

A segunda perspectiva, diz respeito à multiplicidade de linguagens e semioses que se envolvem na produção dos sentidos, na ação social via linguagem, nos gêneros textuais que circulam nos espaços físicos e virtuais, na hibridização de modos de fazer linguagem, modos de ler e produzir textos que mesclam signos linguísticos, imagéticos, índices, links, hiperlinks, sons etc. Trata-se, pois, da multimodalidade como um componente ou dimensão potencializada pelos avanços tecnológicos, pelas novas formas de comunicação, pelas exigências interativas e colaborativas dessas formas (KRESS, 2010; ROJO, 2012). Com efeito, basta pensar nas práticas sociocomunicativas nas quais os (as) discentes estão envolvidos (as), que englobam comunicação por emotions, memes, áudios, vídeos, blogs, vlogs e tantos outros.

Para Rojo (2012), a produção colaborativa de sentidos, mediante a multiculturalidade e multimodalidade, é uma característica central nas novas formas de produção de textos e interações. Com isso, fica patente que as formas de aprender também se alteram, conforme apontam os autores, em razão de novas formas de cognição instauradas.

Assim, a noção de letramento, como conjunto de práticas sociais que interligam pessoas na construção de significado, é absorvida pela pedagogia dos multiletramentos e ampliada na perspectiva de ser uma chave explicativa para a compreensão das redes de práticas e relações que se estabelecem social e comunicativamente. Trata-se, dessa maneira, de um processo ativo, já que 
todo letramento pressupõe algum gênero textual que, por sua vez, se insere num agenciamento de produção, circulação e ação social que é sempre multimidiática (LEMKE, 2010).

Além disso, "precisamos derrubar os limites artificiais que temos tentado criar entre o mental e o material, entre os aspectos individuais e sociais das pessoas e das coisas que interagem física e semioticamente com outras pessoas e coisas" (LEMKE, 2010, p. 460). Nesse contexto, os processos de autoria, análise, exploração e navegação estão inseridos numa profunda articulação entre práticas, redes de relações e instanciações sociais, conforme Lemke (2010), dada a complexificação das tecnologias, das práticas e das habilidades requeridas, como parte de sistemas que dão coesão à sociedade, como um sistema “ecossocial” (LEMKE, 2010).

Todas essas dimensões espraiam-se nos processos educacionais, uma vez que:

\begin{abstract}
A educação é iniciação em comunidades e especialmente em práticas de letramento genéricas e especializadas, novas tecnologias da informação, novas práticas de comunicação e novas redes sociais possibilitam novos paradigmas para a educação e a aprendizagem, e colocam em debate os pressupostos sobre os quais os paradigmas mais antigos se apoiam (LEMKE, 2010, p. 461).
\end{abstract}

Mostra-se, portanto, um consenso quanto à necessidade da educação, da escola e dos (as) docentes adaptarem-se às novas formas de produzir linguagem, colaboração, interação e sentidos, em virtude da própria condição do discente contemporâneo, que já nasce imerso nas novas configurações tecnológicas, comunicacionais e sociais (LEMKE, 2010; ROJO, 2012; SILVA, 2013).

No âmbito educativo, tais processos devem percorrem um longo caminho de consolidação, no que tange ao trato com as TIC e TDIC, embora os (as) discentes contemporâneas já vivem as mudanças no cotidiano. Contudo, a escola e o ensino precisam ressignificar as velhas e novas tecnologias em razão das novas formas de organização da vida, do trabalho, do estudo e de cognição por elas impulsionados, isto é, não se pode desconsiderar a invasão das tecnologias nos processos humanos (PORTO, 2006).

Urge perceber os recursos multimídias como propícios às ações educomunicativas, nos termos de Silva (2013), pelas quais se desenvolvem ações educativas sob a mediação tecnológica. Sob essa perspectiva, "o professor que assume a postura de educomunicador deve reconhecer o potencial dessas tecnologias e criar desafios educativos" (SILVA, 2013, p. 06). Trata-se, pois, de assumir uma cultura de comunicação pela qual as experiências são ressignificadas 
independentemente das condições tecnológicas das escolas com fins à compreensão crítica sobre as práticas e sistemas nos quais estamos imersos (LEMKE, 2010).

Refere-se, de fato, a um tipo de ação e não propriamente à emergência de equipamentos e recursos, embora sejam importante e, conforme postura o referido autor, "uma escola pobre em recursos tecnológicas pode ser rica em educomunicação” (SILVA, 2013, p. 05). Com isso, busca-se a reflexão e problematização das práticas comunicativas mediadas pelas TIC e TDIC com fins, por exemplo, ao "desenvolvimento de novas formas de expressão linguística, enriquecimento curricular e acesso a outras culturas contemporâneas" (SILVA, 2013, p. 03).

Portanto, é nesse conjunto de relações, conceitos e fenômenos que o uso de quaisquer ferramentas digitais precisa ser enfrentado pedagogicamente, como é o caso do Google Forms.

\section{Google Forms como material didático-fonte: algumas aplicações e reflexões}

Em primeiro lugar, o uso dos Google forms se torna interessante pela ausência de custo e pode ser acessado em diferentes aparelhos, gadgets, computadores, celulares etc. Em razão disso, é possível valer-se de diferentes estratégias com os formulários mesclando textos multimodais, áudio e vídeo com variedade de gêneros. Além disso, é possível criar diferentes padrões de atividades para exploração das habilidades atreladas ao uso dos conectores, ou seja, atividades de múltipla escolha, de produção, de preenchimento, dentre outras. Seguindo as colocações de Silva (2013), pode-se conferir dinamismo, interatividade, compartilhamento e outras perspectivas no processo de ensino e aprendizagem de quaisquer conteúdos de ensino.

Com efeito, no que tange aos conectores, Koch (1987), Koch e Elias (2016) e Portolés (2001) afirmam que o (a) docente precisa propor atividades, soluções e estratégias gradativas. Sob essa ótica, as propostas presentes neste trabalho emanam da síntese teórica das proposições dos referidos autores, coadunando com Sánchez e Gómiz (2013) de que o uso adequado dos MD conduz à maturidade linguística e comunicativa.

Retomando a apresentação do formulário Google, vale destacar que a sua interface é de fácil utilização, já que é necessário apenas ter uma conta no site do Google para ter acesso a diversos recursos de uso gratuito. Os formulários são acessados pelo drive do sítio, ferramenta de 
armazenamento de arquivos online, podem ser enviados por e-mails e redes sociais, conforme apresenta-se na imagem ${ }^{2}$ a seguir:

Imagem 2: Interface do Google Formulário

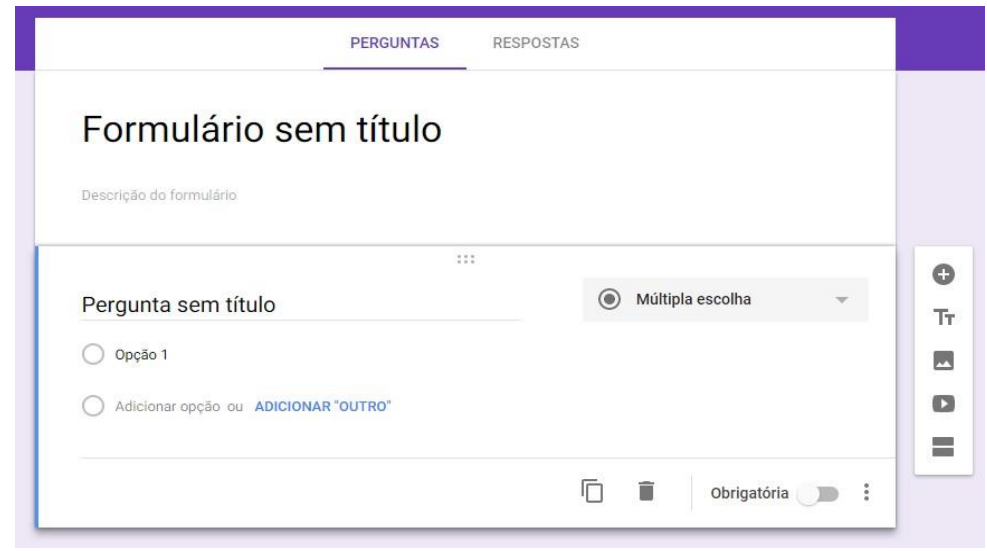

Fonte: docs.google.com

Para os fins desta pesquisa, o formulário Google é assumido como um material-fonte em suporte midiático. A noção de material-fonte foi desenvolvida por Mendes (2012) e voltada para o ensino de língua, notadamente, língua estrangeira com as seguintes caracterizações centrais:

a. Valer-se de abordagem intercultural, voltando-se para a interação com a língua a ser aprendida;

b. Altamente flexíveis, adaptáveis, em diferentes configurações e dificuldades;

c. Menor preocupação com ordenações e seleções, maior preocupação com a forma de aproveitamento;

d. Ser fonte e forma de interação com a linguagem.

A partir de Mendes (2012), Carmo (2015) adapta a noção dos materiais-fonte ao ensino de língua portuguesa agregando uma sistemática voltada à complementariedade dos livros didáticos de português. Para tanto, assume-se uma perspectiva pragmática tanto na forma de construção dos materiais didáticos quanto do ensino de língua portuguesa (OLIVEIRA, 2010).

\footnotetext{
2 Todas as imagens e figuras utilizadas neste trabalho são de domínio público.
} 
No caso do Google forms é possível selecionar imagens, vídeos e outros recursos multimodais na configuração das atividades nos menus dispostos à direita da interface e, com isso, expandir as possibilidades de contato com elementos culturais, discursivos e do universo multissemiótico nos quais, em maior ou menor grau, os MD cooperam para a articulação dos sentidos. Vale destacar quanto aos tipos de configuração das atividades, pois há certa recorrência nas propostas em Koch (1987), Koch e Elias (2016) e Sánchez e Gómiz (2013), a saber:

a. Gradatividade nos tipos de atividades, com leitura e escrita;

b. Estratégias voltadas para identificação, classificação e substituição de MD;

c. Estratégias de preenchimento de enunciados;

d. Uso de gêneros textuais diversos, notoriamente, escritos;

e. Produções escritas voltadas para criação de argumentos, enunciados e sentenças utilizando os MD ou a partir do sentido de um dado marcador.

Neste trabalho, apropriamos dessas recorrências ampliando-as nos seguintes termos: (i) realização de análise contextual do uso do MD em comunicação escrita e falada; (ii) utilização de estratégias de comutação de $\mathrm{MD}$, reordenamento sentencial ou de unidades maiores; (iii) aplicação das estratégias com base nos descritores da Matriz de Referência, uma vez que diversos sistemas de ensino a utilizam como base na construção curricular; (iv) utilização de textos em tipologias, modalidades e gêneros diversos.

Apesar dessas configurações, nada impede que a criatividade docente amplie e altere o que aqui se propõe pela própria natureza dos materiais-fonte e das necessidades pontuais. Importa, entretanto, ter em conta que o processo de conexão textual precisa estar ancorado em diferentes situações comunicativas e não com fins à classificação estanque (GUIMARÃES, 2003).

Sob esse prisma, a elaboração de atividades, sequências didáticas e projetos didáticos devem estar em consonância com os processos pedagógicos maiores (ANTUNES, 2014) e a aplicação das estratégias de forma descontextualizada não faz sentido (ANTUNES, 2014; GUIMARÃES, 2003), já que os materiais-fonte são instrumentos complementares no processo de ensino (MENDES, 2012). Com base nesses pressupostos, tem-se, na sequência, uma apresentação com o conector aditivo: 
Imagem 3: Inserção de imagem de texto

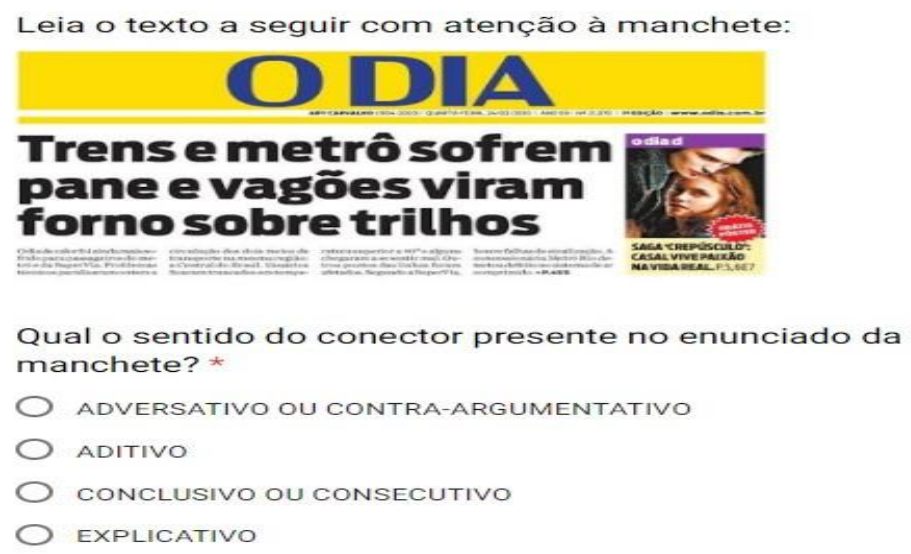

Fonte: <https://descomplica.com.br/blog/portugues/lista-conjuncoes/>. Acesso em: 18 jan. 2018.

A questão de identificação e classificação acima pode ser desdobrada em outra com possibilidade de substituição do conector. $\mathrm{O}$ uso de textos curtos pode facilitar a visualização em diferentes aparelhos eletrônicos, fator que dinamiza o uso do recurso. Além disso, o texto utilizado pode ser trocado por uma manchete em vídeo previamente selecionado e editado, ou que tenha sido utilizado em determinada aula para traçar um recorte que se quer analisar:

Imagem 4: Questão de resposta curta

Preste atenção no recado do vídeo e, em seguida, identifique o conector utilizado determinando seu sentido: *

Sua resposta

Famílias se organizam para economizar no material escolar

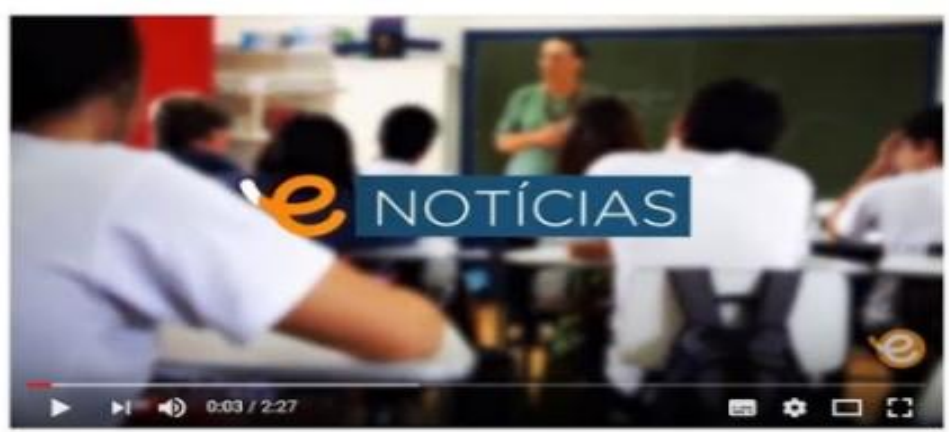


Fonte: 〈https://www.youtube.com/watch?v=KZX-FbW7x1c〉. Acesso em: 18 jan. 2018.

Um trecho do enunciado do vídeo veicula a seguinte mensagem, assim transcrita: "todo início de ano é a mesma coisa: papelarias cheias, crianças escolhendo os materiais e os pais fazendo a conta...". Com base no enunciado o (a) discente realiza uma resposta curta no formulário identificando e determinando o sentido do conector aditivo $e$ presente no trecho. Uma alternativa complementar seria gravar em áudio ou vídeo um momento de interação dos (as) próprios (as) discentes e utilizar esse recurso para que reflitam e analisem o uso que fazem dos MD. Nesse caso, pode ser um momento de debate ou exposição oral crítica, por exemplo. Trata-se, pois, de uma estratégia epilinguística fundamental no desenvolvimento da competência comunicativa (OLIVEIRA, 2010). O importante é fazer com que o (a) discente possa agir e interagir com a linguagem e com os recursos didáticos utilizados para mediar o desenvolvimento da habilidade pretendida (MENDES, 2012).

Na sequência, uma abordagem mesclando o uso de diferentes conectores sob a forma de análise textual e preenchimento. Nesse tipo de atividade a leitura contextual, bem como o conhecimento das funções gerais de cada grupo de conectores são acionadas para execução da atividade:

Imagem 5: Questão de preenchimento

Leia o texto a seguir sobre intolerância religiosa e, sem seguida, determine a melhor sequência de conectores que vinculam os enunciados: *

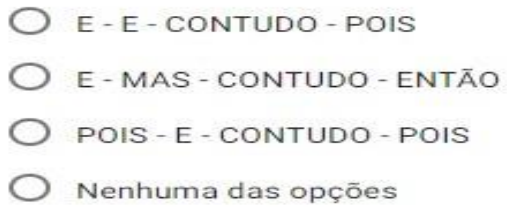

Trecho de uma Redação de ENEM

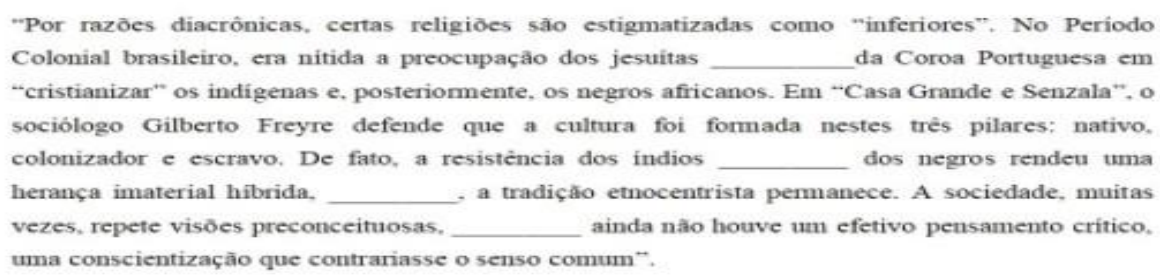


Fonte: <https://geekiegames.geekie.com.br/blog/como-fazer-uma-redacao-nota-1000/>. Acesso em: 18 jan. 2018.

Para o estudo do encaixamento e vinculação semântica dos enunciados, outra possibilidade é a atividade de reordenamento, com a qual é possível tratar dos sentidos dos MD na íntima relação com o contexto enunciativo e propiciar a análise de diferentes caminhos para o encadeamento. Dessa forma, o (a) discente pode perceber o significado procedimental dos conectores e a vinculação pragmática entre os enunciados:

Imagem 6: Questão de análise e reordenamento

Reordene os enunciados a seguir utilizando diferentes

conectores para estabelecer a coesão sequencial e a vinculação

entre as ideias. Atenção! Há várias possibilidades de

encadeamento: *

Sua resposta

A saúde no Brasil vai de mal a pior

Os salários dos médicos estão muito baixos

Os remédios estão muito caros

Ninguém suporta mais tantas filas em hospitais.

Fonte: 〈http://redijamelhor.blogspot.com.br/p/coesao.html〉. Acesso em: 18 jan. 2018.

Outra estratégia constitui-se em estabelecer enunciados nos quais os conectores foram intencionalmente trocados por outros não correlatos. Com isso, é possível levar à percepção das relações semânticas no processo de leitura. Pode-se, ainda, solicitar ações de substituição, reescrita e explanação dos sentidos vinculados. Dessa forma, com a técnica semelhante ao cloze, aprofunda-se a consciência do uso e do significado procedimental dos MD (PORTOLÉS, 2001).

Embora o que se mostra nas estratégias acima focaliza o processo de estruturação e as relações intrínsecas dos enunciados, as discussões relativas aos temas presente nos textos podem ser realizados como forma adicional, isto é, dedicando questões que aprofundem a discussão do conteúdo do texto. No entanto, interessa aqui mostrar, de forma mais detida, estratégias 
específicas para o entendimento das relações estabelecidas localmente pelos MD, seus significados procedimentais, funções prototípicas e formas de trato pedagógico para o desenvolvimento das diferentes habilidades de leitura e interpretação dessas funções.

No exemplo a seguir, tem-se um texto narrativo prévia e intencionalmente construído para direcionar a atenção nas relações contra-argumentativas. $\mathrm{O}$ texto pode ser adaptado para o trato com os demais tipos de conectores, bem como pode-se utilizar outra tipologia que não a narração como, por exemplo, um texto argumentativo. A troca intencional dos conectores deve levar ao estranhamento no percurso inferencial que se realiza na leitura (KOCH, 1987; PORTOLÉS, 2001). Sob esse prisma, somente pela percepção dos sentidos dos enunciados é que se pode inferir as relações de oposição e restrição que dão base à articulação dos enunciados do texto a seguir:

Imagem 7: Texto narrativo

\section{Conectores Argumentativos}

INDIQUE E EXPLIQUE QUANTO AOS CONECTORES INCORRETAMENTE EMPREGADOS

Joăo sempre se dedicou aos esportes, APESAR DE nunca ter feito curso profissional. Desde pequeno participava dos jogos escolares desenvolvendo-se muito na adolescência. ALÉM DISSO, até agora ninguém se interessou em contratá-lo. Por essa razão, resolveu procurar quem pudesse apostar em seu potencial procurando em várias equipes alguma oportunidade, MAS năo obteve sucesso ainda. Depois de muita procura, o jogador encontrou um caça talentos resolveu investir nele. $O$ salário não era dos melhores, PORQUE já dava certa independência dando-lhe tempo para treinar muito. Afinal, o sucesso começa com oportunidades. ENFIM, não sem esforçarse.

Sua resposta

\section{ENVIAR}

Fonte: criado pelo autor no Google Forms

Uma vez que o texto foi criado para focar nos conectores contra-argumentativos, é na leitura que o (a) discente deve perceber que os conectores além disso, porque e enfim não realizam a vinculação esperada e, por essa razão, precisam ser substituídos. Igualmente, o texto pode ajudar a desenvolver o repertório de uso dos diferentes conectores de um subgrupo específico e observar a especialidade de seus sentidos. 
O Google forms conta ainda com o formato de grade de múltipla escolha que permite a criação de questões com colunas e alternativas. Com essa configuração pode-se tratar, por exemplo, das relações lógico-semânticas, conforme Antunes (2005) e Koch (1987; 2010), para percepção tanto do encaixamento das sentenças, quanto da vinculação dos sentidos estabelecidos pelos conectores. Chamam-se relações lógico-semânticas aquelas "marcadas pelos encadeadores de discurso, responsáveis pelo encadeamento sucessivo de enunciados" (KOCH, 1987, p. 89). Observe no exemplo abaixo:

Imagem 8: Relações lógico-semânticas

\section{Conectores Argumentativos}

Relaçōes lógico-semãnticas

Relacione as colunas considerando o sentido entre as sentenças:

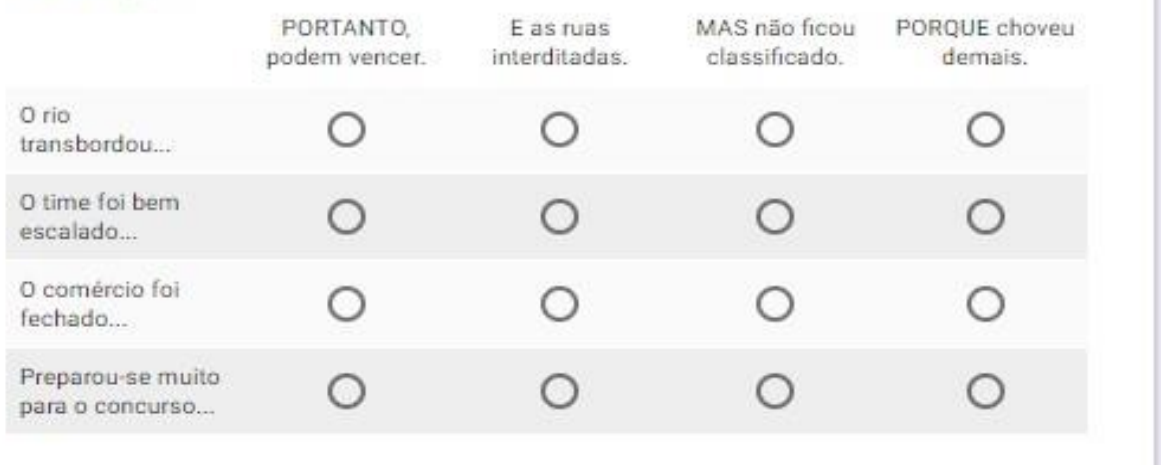

Fonte: criado pelo autor no Google Forms

Além das configurações mostradas acima, os formulários podem ser utilizados para a criação de quizes no formato de testes e jogos. Em todo caso, o uso dos materiais-fonte, como é o caso da presente proposta com o Google Forms, precisa se articular no interior de projetos didáticos, atividades de leitura e sob a égide de um planejamento para que se determine as atividades com base nas necessidades discentes, como também para não haver uma abordagem descontextualizada e estanque (ANTUNES, 2014; GUIMARÃES, 2003). 
Mais ainda, pode-se inserir as estratégias aqui propostas como parte dos módulos que compõem uma sequência didática de gênero, conforme Dolz, Noverraz e Schneuwly (2004) e, nesse caso, os textos escolhidos podem estar relacionados numa mesma tipologia, por exemplo, selecionar gêneros textuais da ordem do argumentar sejam eles falados, escritos ou multimodais, ou mesmo seguindo uma determinada temática. Segundo os referidos autores, os módulos são constituídos por atividades e outras ações destinadas a criar instrumentos para o domínio dos problemas colocados pelo gênero textual (DOLZ; NOVERRAZ; SCHNEUWLY, 2004). Dessa forma, "em cada módulo, é muito importante propor atividades as mais diversificadas, por diferentes vias" (DOLZ; NOVERRAZ; SCHNEUWLY, 2004, p. 89) Em suma, é preciso apropriar-se da flexibilidade da proposta aqui apresentada para adequá-la à realidade do próprio processo de ensino e aprendizagem e como forma de garantir as chances de sucesso no que concerne ao domínio das habilidades propostas nos módulos, conforme apontam os autores supracitados.

A título de exemplo, considere-se uma possível sequência didática voltada para o ensino e estudo do gênero redação de ENEM, que dispõe de sua caracterização enquanto gênero textual situado num contexto social específico, formas de produção, composição e circulação determinados, além de funções retórico-argumentativas próprias (OLIVEIRA, 2016). Para o trato desse gênero, uma sequência didática pode ser construída, tal como concebido por Dolz, Noverraz e Schneuwly (2004):

Imagem 09: Sequência didática de gênero
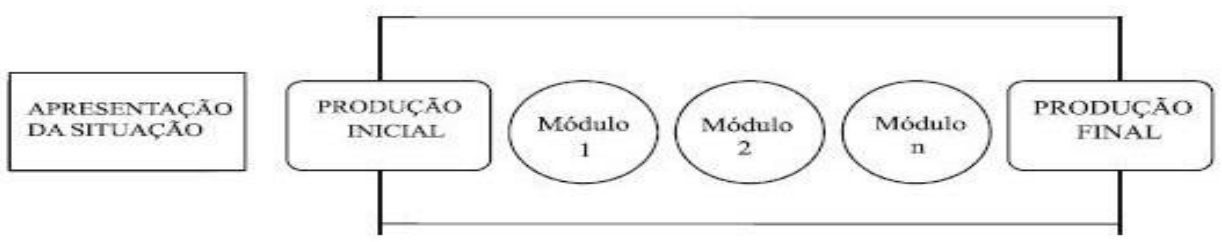

Fonte: Dolz, Noverraz e Schneuwly (2004, p. 98)

Assim, conforme mencionado anteriormente, um dos módulos pode ser construído para aprofundamento do uso dos conectores, como parte das estratégias argumentativas (KOCH; 
ELIAS, 2016). Nesse contexto, o uso do Google Forms, como prática de multiletramento, pode ser aplicado numa das etapas da sequência didática. Conforme o esquema didático, seria feita a apresentação da situação social na qual o gênero é produzido e circula, bem como tem-se o contato com textos representativos. A partir de uma produção inicial são concebidos e articulados tantos módulos quanto necessários para tratar das diferentes dimensões do gênero em estudo. Dessa maneira, conforme a necessidade apresentada pelos (as) discentes, constroem-se atividades-fontes com o Google Forms para aprofundar a reflexão e uso dos conectores no gênero textual em estudo. Textos de alunos ou outros representativos disponíveis na web podem ser utilizados para ações epilinguísticas, isto é, reflexão sobre as próprias produções.

Vale salientar que a criatividade e a capacidade de adaptação são imprescindíveis para quaisquer propostas didáticas. Nesses termos, consoante Oliveira e Alencar (2012) o docente é o ator fundamental no desenvolvimento do próprio potencial criativo e, concomitantemente, dos discentes. Sob essa ótica, "a escola precisa ser um espaço que cultive e valorize as ideias originais de seus educadores, oportunizando o desenvolvimento e o desabrochar de habilidades que muitas vezes esse profissional desconhece possuir" (OLIVEIRA; ALENCAR, 2012, p. 543).

Além disso, "no trabalho com a linguagem, pois, não se pode perder de vista as especificações dos contextos de uso da fala e da escrita", conforme sinaliza Antunes (2014, p. 55) e esses contextos estão cada vez mais híbridos (ANTUNES, 2014). Diante disso, a presente proposta visa atender essas especificações, bem como na compreensão de que não existem receitas, mas deve o docente ter consciência de quais são os pressupostos teóricos e quais concepções de língua e linguagem que adota para adequar suas metodologias (ANTUNES, 2014; OLIVEIRA, 2010). Nesses termos:

Tudo está muito conectado no trabalho pedagógico: as atividades são decorrentes dos objetivos que escolhemos, esses são decorrentes das concepções que temos acerca de como são as línguas, que relações têm com outros objetivos da criação humana, que funções desempenham, enfim. Concepções, objetivos, tipos de abordagem, práticas pedagógicas, atividades: tudo é uma cadeia. (ANTUNES, 2014, p. 60).

Portanto, eventos de multiletramento, ações epilinguísticas e metalinguísticas devem se articular visando à interação social via linguagem, tendo o texto como ponto de partida, a análise cotextual e contextual intimamente relacionadas. Nesse âmbito, valer-se do uso de textos em gêneros e modalidades diversas, preferencialmente curtos, porquanto propicia-se facilidade de 
uso, por exemplo, no caso do acesso ao formulário se efetivar em aparelhos celulares. Tal fator deve tornar a leitura mais ágil e a atividade ganha interesse na mudança de suporte, dado o fato de aparelhos celulares estarem sempre à mão e a facilidade dos discentes em lidar com o aparato tecnológico (DORNELES; MAGALHÃES; SILVA JÚNIOR, 2011).

Vale destacar que o uso dessas estratégias também facilita o processo de correção e avaliação do ensino e da aprendizagem, já que na construção das questões pode-se determinar as respostas possíveis no próprio formulário, mediante correção automática no caso dos testes construídos com múltipla escolha, caixas de seleção ou lista suspensa, ou com feedback no caso dos modos resposta curta e parágrafo. Com isso, o docente também ganha em tempo, considerando que a demanda de trabalho é sempre substancial.

Mais ainda, a proposta pode ser um valioso instrumento de avaliação mediadora, nos termos de Hoffman (1993), uma vez que os erros apresentados e contabilizados nos formulários podem servir de parâmetro para o trabalho focado nas dificuldades apresentadas e, sob essa ótica, os erros se convertem em oportunidade para uma avaliação não classificatória, mas com fins a desenvolver aquilo que se apresentar mais carente, isto é, " a tentativa é no sentido de inverter a hierarquia tradicional onde o acerto é valorizado [...] e o erro punido em todas as circunstâncias" (HOFFMAN, 1993, p. 113). Conforme essa autora, entre uma atividade e a posterior, a ação mediadora se efetiva, já que a estratégia visa o aperfeiçoamento do saber discente e não a atribuição de conceitos ou notas relativos ao desempenho em si mesmos.

\section{Considerações Finais}

O presente artigo tratou do ensino dos marcadores discursivos mediante uso dos formulários do Google ancorando-se na perspectiva da pedagogia dos multiletramentos. Foram apresentados os conceitos e exemplares dos conectores argumentativos como conteúdo a ser trabalhado em diferentes configurações e ferramentas dispostas no formulário, além da diversificação dos gêneros textuais e habilidades voltadas para o desenvolvimento da competência discursiva, notadamente, no que tange à coesão sequencial.

Discutiu-se da importância dos multiletramentos apontando sugestões de diferentes usos do Google Forms assumindo-o como um tipo de material-fonte e a proposta como um protótipo 
didático flexível. Com isso, a criatividade docente e as necessidade pontuais são fundamentais para o uso, adaptação e ampliação do que aqui foi exposto. Nessa perspectiva, importa endossar que é a necessidade ou dificuldade de cada discente que apontará o necessário para a elaboração das diferentes estratégias. Em todo caso, o presente trabalho buscou ampliar as propostas de didatização dos MD num esforço de problematização metodológica.

Por fim, independentemente das diferentes dificuldades que os (as) docentes enfrentem quanto à disponibilidade e qualidade dos recursos tecnológicos no espaço escolar, é fundamental compreender as constrições impostas no cotidiano pelas tecnologias e preparar-se continuamente para lidar com as novas formas de interação, comunicação e cognição das quais os (as) discentes já vivem e das quais precisamos nos apropriar como estratégias educativas.

\section{Referências}

ALOMBA RIBEIRO, M. D’A. Los conectores argumentativos en los aprendices hispa-nohablantes de português. 2005. 271 f. Tese (Linguística Aplicada) - Departamento de Filologia, Universidade de Alcalá, Alcalá de Henares, 2005.

ANSCOMBRE, J. C.; DUCROT, O. La argumentación en la lengua. Editorial Gredos: Madrid, 1994.

ANTÔNIO, J. D. A sinalização das relações de coerência por conectores torna a identificação das relações mais fácil? Uma investigação do reconhecimento das relações pelos destinatários do discurso. RELIN, v. 24, n. 1, p. 293-326, 2016.

ANTUNES, I. Lutar com palavras: coesão e coerência. São Paulo: Parábola Editorial, 2005.

Editorial, 2014.

Gramática contextualizada: limpando o pó das ideias simples. São Paulo: Parábola

AUSTIN, J. L. Quando dizer é fazer: palavras e ação. Trad. De Danilo Marcondes de Souza filho. Porto Alegre: Artes Médicas, 1990.

BLAKEMORE, D. Indicators and procedures: nevertheless and but. J. Linguistics, Cambrigde, v. 36. 463-486. 2000.

CARMO, B. B. S.; ALOMBA RIBEIRO, M. D. Os marcadores discursivos na educação básica: necessidade de sistematização a partir do livro didático. Fórum Linguístico, Florianópolis, v. 11, n. 4, p. 457-473, dez. 2014. 
. Hot potatoes como apoio didático no ensino dos marcadores discursivos. Língu@ Nostr@, Canoas, v. 4, n. 1, p. 17-34, jan.-jun. 2016.

CARMO, B. B. S. A sistematização dos conectores contra-argumentativos na concepção do material didático. 2015. 158 f. Dissertação (Mestrado em Letras) - Programa de Mestrado Profissional em Letras, Universidade Estadual de Santa Cruz, Ilhéus, 2015.

DIJK, T. A. Cognição, discurso e interação (org. e apresentação de Ingedore V. Koch). 6. ed. 1. reimpressão. São Paulo: Contexto, 2008.

DOLZ, J.; NOVERRAZ, M.; SCHNEUWLY, B. Sequências didáticas para o oral e as escrita: apresentação de um procedimento. In: SCHNEUWLY, B.; DOLZ, J. (Orgs.) Gêneros orais e escritos na escola. Trad. De Roxane Rojo e Glaís Sales Cordeiro. Campinas: Mercado das Letras, 2004, p. 81-108.

DORNELES, D. M.; MAGALHÃES, F. P. P.; SILVA JÚNIOR, N. L. O ensino de língua portuguesa e as TICS. Revista Philologus, Rio de Janeiro, ano 17, n. 51, set./dez. 2011.

FONTANA, F. F.; CORDENONSI, A. Z. TDIC como mediadora do processo de ensino-aprendizagem da arquivologia. Ágora, Florianópolis, v. 25, n. 51, p. 101-131, jul./dez. 2015.

FORTES, F. S. Os marcadores discursivos no latim: considerações pragmáticas e textuais sobre as preposições, interjeições e conjunções latinas em Donato e Prisciano. 2004. 130 f. Dissertação de Mestrado. Departamento de Letras Clássicas e Vernáculas da Faculdade de Filosofia, Letras e Ciências Humanas. Universidade de São Paulo.

GUIMARÃES, V. C. A conexão textual em LDs de $5^{\mathrm{a}}$ a $8^{\mathrm{a}}$ séries do ensino fundamental: uma tentativa de formulação de uma gramática textual. In: ROJO, R.; BATISTA, A. A. G. (orgs.) Livro didático de língua portuguesa: letramento e cultura da escrita. Campinas: Mercado das Letras, 2003, p. 153-166.

GRICE, H. P. Logic and conversation. In: PETER, C.; MORGAN, J. Syntax and semantics. Speech acts. New York: Academic Press, v. 03, p. 41-53, 1975.

HOFFMANN, J. Avaliação mediadora: uma prática em construção da pré-escola à universidade. 18 ed. Porto Alegre: Educação e Realidade, 1993.

KOCH, I. G. V. Dificuldades na leitura/produção de textos: os conectores interfrásticos. In: STAUB, A.; CLEMENTE, E. (orgs.). Linguística aplicada ao ensino de português. Porto Alegre: Mercado Aberto, 1987, p. 83-98. A coesão textual. 22 ed. São Paulo: Contexto, 2010. 
. ELIAS, V. M. Escrever e argumentar. São Paulo: Contexto, 2016.

KRESS, G. Multimodality: a social approach to contemporary communication. London: Routledge, 2010.

LEMKE, J. L. Letramento metamidiático: transformando significados e mídias. Trab. linguist. apl., v.49, n.2, p.455-479, 2010.

MARTELOTTA, Mário E. Mudança linguística: uma abordagem baseada no uso. São Paulo: Cortez, 2011.

MENDES, E. Aprender a ser e a viver com o outro: materiais didáticos interculturais para o ensino de português LE/L2. In: SHEYERL, D.; SIQUEIRA, S. (orgs.). Materiais didáticos para o ensino de línguas na contemporaneidade: contestações e proposições. Salvador: EDUFBA, 2012, p. 355-378.

MONDADA, L; DUBOIS, D. Construção dos objetos de discurso e categorização: uma abordagem dos processos de referenciação. In: CAVALCANTI, M; RODRIGUES, B; CIULLA, A. (Org.). Referenciação. São Paulo: Contexto, 2016, p. 17-52.

MORAIS, M. F. A. Marcadores da estruturação textual: elementos para a descrição do papel dos marcadores discursivos no processamento cognitivo do texto. Vila Real: Publito Artes Gráficas, 2011.

NEVES, M. H. M. Gramática de usos do português. São Paulo: Editora UNESP, 2000, 4 reimpressão.

OLIVEIRA, L. A. Coisas que todo professor de português precisa saber: a teoria na prática. São Paulo: Parábola Editorial, 2010.

OLIVEIRA, F. C. C. Um estudo sobre a caracterização do gênero redação do ENEM. 2016. 166 f. Tese (doutorado) - Universidade Federal do Ceará, Programa de Pós-Graduação em Linguística, Fortaleza, 2016.

OLIVEIRA, E. B. P.; ALENCAR, E. M. L. S. Importância da criatividade na escola e no trabalho docente segundo coordenadores pedagógico. Estudos de Psicologia, Campinas, v. 29, n. 04, p. 541-552, out./dez., 2012.

PENHAVEL, E. O que diferentes abordagens de marcadores discursivos têm em comum? (Con)Textos Linguísticos, Vitória, v.6, n.7, p. 78-98, 2012.

PORTOLÉS, J. Marcadores del discurso. Barcelona: Ariel S.A., 2001.

PORTO, T. M. E. As tecnologias de comunicação e informação na escola; relações possíveis... relações construídas. Revista Brasileira de Educação, v. 11 n. 31 jan./abr., 2006. 
ROJO, R. Pedagogia dos multiletramentos: diversidade cultural e de linguagens na escola. In: ROJO, R.; MOURA, E. (orgs.) Multiletramentos na escola. São Paulo: Parábola Editorial, 2012, p. 11-31.

ROJO, R.; MOURA, E. (orgs.). Multiletramentos na escola. São Paulo: Parábola, 2012.

SÁNCHEZ, M. M.; GÓMIZ, S. F. Los marcadores discursivos. Madrid: Editorial Edinumen, 2013.

SILVA, B. A. O uso pedagógico de TIC em Centro de Estudos de Língua, no ensino público de Assis / SP. Revista Tecnologias na Educação, n. 9, dez. 2013.

SPERBER, D.; WILSON, D. Relevância: comunicação e cognição. Fundação Calouste Gulbenkian: Lisboa, 2001.

THE NEW LONDON GROUP. A pedagogy of multiliteracies: designing social futures. The Harvard educational review, v. 1, 1996. Disponível em:

<http://www.sfu.ca/ decaste/newlondon.htm>. Acesso em: 11 dez. 2017.

URBANO, H. Aspectos basicamente interacionais dos marcadores discursivos. In: NEVES, Maria Helena de Moura (Org.) Gramática do Português Falado. 2. ed. v. 07: Novos estudos. São Paulo: Editora Unicamp, 1999, p. 195-258.

Recebido em 30 de maio de 2018. Aceito em17 de setembro de 2018. 